\title{
CRYSTAL STRUCTURE OF TRIPHENYLTIN ISOPROPYLXANTHATE QUINOLINE N-OXIDE
}

\author{
Seik Weng Ng${ }^{1}$, V.G. Kumar Das ${ }^{2}$ and Michael G.B. Drew ${ }^{3}$ \\ 1 Institute of Advanced Studies \\ 2 Department of Chemistry, University of Malaya, 59100 Kuala Lumpur, Malaysia \\ ${ }^{3}$ Department of Chemistry, University of Reading, Reading RG6 2AD, UK
}

\begin{abstract}
The geometry of the tin atom in triphenyltin isopropylxanthate quinoline $N$-oxide is a distorted trans- $\mathrm{C}_{3} \mathrm{SnOS}$ trigonal bipyramid ( $\mathrm{Sn}-\mathrm{C}=2.119(3)$, 2.125(3), 2.128(3), Sn-O = 2.448(4), Sn-S = 2.544(2) $\AA$; O-Sn-S = 167.4(1) ${ }^{\circ}$ ). The structure represents an unusual example of a Lewis-acidic sulfidoorganotin compound.
\end{abstract}

\section{Introduction}

Among triorganotin compounds, higher-than-four coordination at tin is not often realized when a sulfur atom is linked covalently to the metal atom [1], as exemplifed by the triphenyltin monothiocarbamato [2], dithiocarbamato [3] and isopropylxanthato [4] derivatives and the 2-mercaptobenzoatotriphenylstannate anion [5], all of which display essentially tetrahedral configurations at tin.

It was of interest to investigate the claim [6] based on spectroscopic evidence that triphenyltin ethylxanthate shows Lewis acidic behavior towards amine oxides. The synthesis of the quinoline $\mathrm{N}$-oxide adduct of triphenyltin isopropylxanthate was undertaken for a crystal structure determination, the results of which are reported here. 


\section{Experimental}

Triphenyltin chloride, potassium isopropylxanthate and quinoline $N$-oxide hydrate (1/1/1 molar ratio) were heated in a small volume of chloroform. The mixture was filtered to remove the precipitated potassium chloride, and the solvent removed to give an oil. The oil was dissolved in a chloroform/petroleum ether $(60$ $-80^{\circ} \mathrm{C}$ ) mixture; slow evaporation of the solvent afforded large yellow crystals of the complex, m.p. $110^{\circ} \mathrm{C}$. Analysis. Found: C, 58.90; H, 4.65; N, 2.19\%. Calc. for $\mathrm{C}_{31} \mathrm{H}_{29} \mathrm{NO}_{2} \mathrm{~S}_{2} \mathrm{Sn}: \mathrm{C}, 59.07 ; \mathrm{H}, 4.64 ; \mathrm{N}, 2.22 \%$. Tin- $119 m$ Mössbauer $(78 \mathrm{~K})$ : Isomer Shift $=1.29 \mathrm{mms}^{-1}$ (relative to $\mathrm{CaSnO}_{3}$ ), Quadrupole Splitting $=2.74 \mathrm{~mm}$ $\mathrm{s}^{-1}, \Gamma_{1}=0.89, \Gamma_{1}=0.89 \mathrm{~mm} \mathrm{~s}^{-1}$.

The 8463 reflections were measured on a MAR Research Image Plate System equipped with Mo-K $\alpha(0.71073 \AA)$ radiation (collection range: $-19 h<19$, $0 \leq k \leq 14,-19 \leq l<19)$ to $2 \Theta=50^{\circ}$. The crystal was positioned at $75 \mathrm{~mm}$ from the Image Plate in a random orientation; 95 frames were measured at $2 \mathrm{deg}$ intervals with a counting time of 2 min. Data analysis was carried out with the XDS program [7]. The structure was solved by the Patterson method [8]. There was some disorder in the phenyl and quinolinyl groups, and refinement of the mode without constraints led to unsatisfactory distances in these groups, which were instead refined as idealized groups. Non-H atoms were refined anisotropically; $\mathrm{H}$-atoms were generated and were allowed to ride on their parent $\mathrm{C}$-atoms with temperature factors 1.5 times those of their parent atoms. Full-matrix least-squares refinement on $F^{2}$ [9] for 275 variables and at an OMIT level of 4 in SHELXL-93 converged with a shift-to-error ratio of less than 0.001 to $R_{1}=0.0415$ for the 3677 indepedent $F_{0}>4 \sigma\left(F_{0}\right)$ reflections. The final difference map had peaks from 0.67 to $-0.66 e \AA^{-3}$. Atomic coordinates are listed in Table 1.

Crystal data: $\mathrm{C}_{31} \mathrm{H}_{29} \mathrm{NO}_{2} \mathrm{~S}_{2} \mathrm{Sn}, \quad F W=630.35$, monoclinic, $P 2_{1} / a$ (non-standard No. 14), $a=16.264(5), b=11.874(5), c=16.434(5) \AA, \beta=$ $116.66(5)^{\circ}, V=2836.2 \AA^{3}, F(000)=2836.2, D_{\text {calc }}=1.477 \mathrm{~g} \mathrm{~cm}^{-3}, \mu(\operatorname{Mo} K \alpha)=1.08$ $\mathrm{mm}^{-1}$ for $Z=4$.

\section{Results and discussion}

Triphenyltin isopropylxanthate forms with quinoline $N$-oxide a $1 / 1$ complex whose tin-119m Mössbauer parameters (IS $=1.29, \mathrm{QS}=2.74 \mathrm{~mm} \mathrm{~s}^{-1}$ ), which are similar to those $\left(\mathrm{IS}=1.26, \mathrm{QS}=3.11 \mathrm{~mm} \mathrm{~s}^{-1}\right)$ of the structurally characterized tri$p$-tolyltin bromide adduct of this amine-oxide [10], imply five-fold coordination at tin. The tin-sulfur distance $(2.544(2) \AA$ ) in the xanthate complex (Fig. 1) is 
Table 1. Atomic coordinates and equivalent ${ }^{a}$ isotropic temperature factors for triphenyltin isopropylxanthate quinoline $\mathrm{N}$-oxide

\begin{tabular}{lllll}
\hline Atom & $x$ & $y$ & $z$ & $U_{\text {eq }}$ \\
\hline & & & & \\
Sn1 & $0.37182(2)$ & $0.02595(3)$ & $0.22459(2)$ & $0.0400(2)$ \\
S1 & $0.5104(1)$ & $-0.0494(1)$ & $0.2090(1)$ & $0.0566(4)$ \\
S2 & $0.6448(1)$ & $0.0660(2)$ & $0.1625(2)$ & $0.0936(7)$ \\
O1 & $0.4714(3)$ & $0.1203(4)$ & $0.1062(3)$ & $0.055(1)$ \\
O2 & $0.2526(3)$ & $0.0738(3)$ & $0.2703(3)$ & $0.0521(9)$ \\
N1 & $0.2074(3)$ & $-0.0054(4)$ & $0.2902(3)$ & $0.039(1)$ \\
C1 & $0.2694(4)$ & $0.0360(4)$ & $0.0873(4)$ & $0.043(1)$ \\
C2 & $0.2690(4)$ & $-0.0368(5)$ & $0.0234(4)$ & $0.057(2)$ \\
C3 & $0.2067(5)$ & $-0.0267(6)$ & $-0.0669(5)$ & $0.070(2)$ \\
C4 & $0.1460(5)$ & $0.0594(7)$ & $0.0935(4)$ & $0.068(2)$ \\
C5 & $0.1463(4)$ & $0.1337(7)$ & $-0.0311(4)$ & $0.071(2)$ \\
C6 & $0.2068(4)$ & $0.1237(5)$ & $0.0587(4)$ & $0.056(1)$ \\
C7 & $0.3821(3)$ & $-0.1234(4)$ & $0.3015(3)$ & $0.039(1)$ \\
C8 & $0.3314(5)$ & $-0.2175(5)$ & $0.2608(4)$ & $0.064(2)$ \\
C9 & $0.3370(6)$ & $-0.3107(5)$ & $0.3100(5)$ & $0.077(2)$ \\
C10 & $0.3942(5)$ & $-0.3152(6)$ & $0.4003(5)$ & $0.073(2)$ \\
C11 & $0.4473(5)$ & $-0.2214(5)$ & $0.4416(4)$ & $0.062(2)$ \\
C12 & $0.4395(4)$ & $-0.1266(5)$ & $0.3938(4)$ & $0.047(1)$ \\
C13 & $0.4267(3)$ & $0.1837(4)$ & $0.2863(3)$ & $0.038(1)$ \\
C14 & $0.3692(4)$ & $0.2688(4)$ & $0.2892(4)$ & $0.049(1)$ \\
C15 & $0.4040(5)$ & $0.3739(5)$ & $0.3217(5)$ & $0.063(2)$ \\
C16 & $0.4949(5)$ & $0.3969(5)$ & $0.3538(4)$ & $0.068(2)$ \\
C17 & $0.5524(5)$ & $0.3132(7)$ & $0.3544(4)$ & $0.072(2)$ \\
C18 & $0.5196(4)$ & $0.2063(6)$ & $0.3204(4)$ & $0.057(2)$ \\
C19 & $0.5406(4)$ & $0.0539(5)$ & $0.1542(4)$ & $0.050(1)$ \\
C20 & $0.5100(5)$ & $0.3158(6)$ & $0.1092(6)$ & $0.086(2)$ \\
C21 & $0.4793(4)$ & $0.2121(6)$ & $0.0525(4)$ & $0.061(2)$ \\
C22 & $0.3879(5)$ & $0.2237(7)$ & $-0.0273(5)$ & $0.091(2)$ \\
C23 & $0.1443(4)$ & $-0.0682(5)$ & $0.2244(4)$ & $0.054(1)$ \\
C24 & $0.0963(4)$ & $-0.1501(5)$ & $0.2417(5)$ & $0.064(2)$ \\
C25 & $0.1109(4)$ & $-0.1685(5)$ & $0.3288(5)$ & $0.065(2)$ \\
C26 & $0.1773(4)$ & $-0.1047(4)$ & $0.4003(4)$ & $0.048(1)$ \\
C27 & $0.1955(5)$ & $-0.1186(7)$ & $0.4925(5)$ & $0.070(2)$ \\
C28 & $0.2585(6)$ & $-0.0531(8)$ & $0.5575(5)$ & $0.078(2)$
\end{tabular}



C29
$0.3065(5)$
$0.0290(6)$
$0.5350(5)$
$0.072(2)$
C30
$0.2904(4)$
$0.0459(5)$
$0.4472(4)$
$0.052(1)$
C31
$0.2255(3)$
$-0.0218(4)$
$0.3804(4)$
$0.039(1)$

${ }^{a} U_{\text {eq }}$ is defined as one third of the trace of the orthogonalized $\mathbf{U}_{\mathrm{ij}}$ tensor.

noted to be longer than that $(2.445(1) \AA$ ) in the parent Lewis acid [4] molecule. Triphenyltin isopropylxanthate itself shows a distorted tetrahedral geometry as a result of an intramolecular contact of 2.950(3) $\AA$; the tin-oxygen interaction is apparently preferred to a tin-sulfur interaction owing to packing effects [11].

The triphenyltin girdle in the quinoline $N$-oxide complex is planar ( $\Sigma$ $\left.\mathrm{C}-\mathrm{Sn}-\mathrm{C}=357.0(3)^{\circ}\right)$; the oxygen atom of the xanthate anion appears to be forced further (3.241(3) $\AA$ ) away from the metal atom. Other non-bonding interactions are not found in the crystal structure.

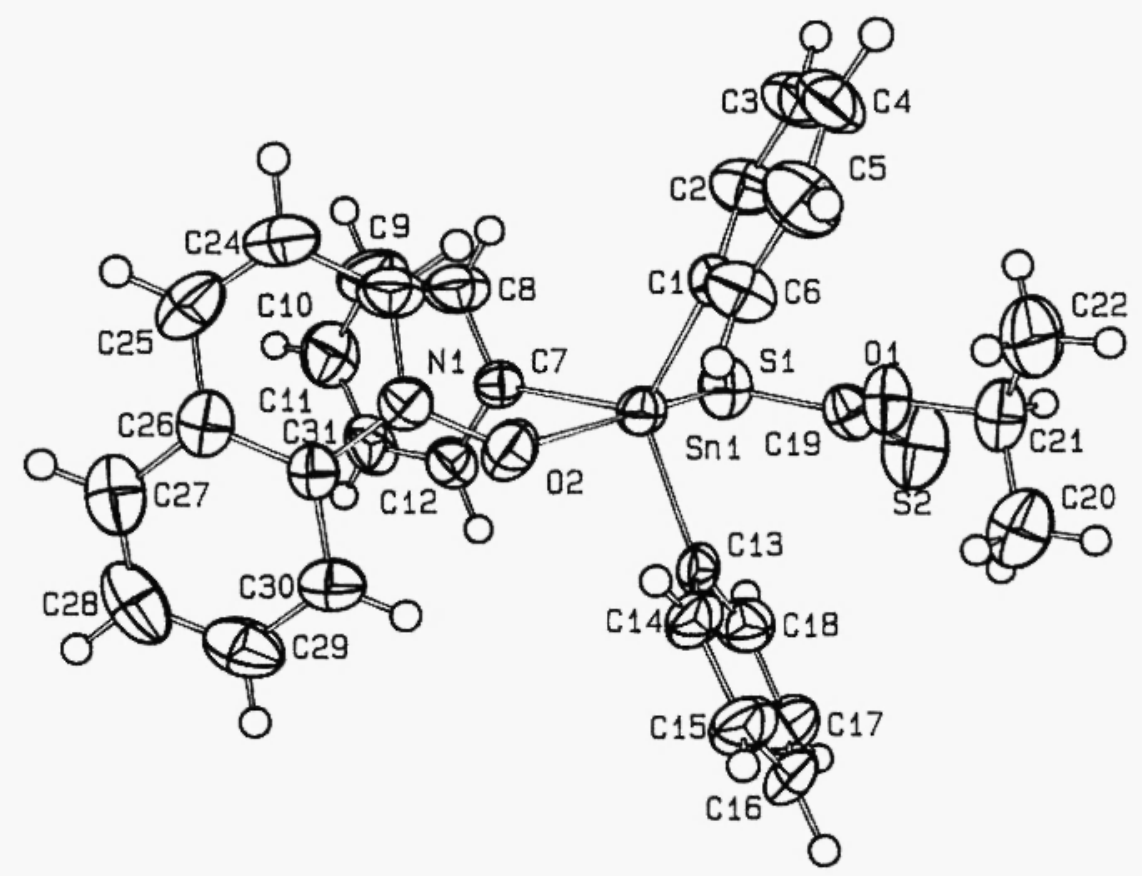

Fig. 1. Geometry of the tin atom in triphenyltin isopropylxanthatequinoline $N$-oxide. Selected bond distances and angles: $\mathrm{Sn} 1-\mathrm{C} 1=2.119(3), \mathrm{Sn} 1-\mathrm{C} 7=2.125(3), \mathrm{Sn} 1-\mathrm{C} 13=$ 2.128(3), Sn1-O2 = 2.448(4), Sn1-S1 = 2.544(2) Aं; C1-Sn1-C7 = 119.7(1), C1-Sn1-C13 $=114.8(1), \mathrm{C} 1-\mathrm{Sn} 1-\mathrm{O} 2=87.9(1), \mathrm{C} 1-\mathrm{Sn} 1-\mathrm{S} 1=102.5(1), \mathrm{C} 7-\mathrm{Sn} 1-\mathrm{C} 13$ 122.5(1), $\mathrm{C} 7-\mathrm{Sn} 1-\mathrm{O} 2=82.7(1), \mathrm{C} 7-\mathrm{Sn} 1-\mathrm{S} 1=86.0(1), \mathrm{C} 13-\mathrm{Sn} 1-\mathrm{O} 2=82.3(1), \mathrm{C} 13-\mathrm{Sn} 1-\mathrm{S} 1=$ 99.3(1), O2-Sn1-S1 = 167.4(1) . 
The tin-oxygen bond distance (2.448(4) $\AA$ ) compares well with those found in the quinoline $\mathrm{N}$-oxide adducts of the triphenyltin derivatives of benzisothiazol-3(2H)-one 1,1-dioxide ( $\mathrm{Sn}-\mathrm{O}=2.319(6) \AA)[12]$ and succinic acid $(\mathrm{Sn}-\mathrm{O}=2.409(8) \AA)[13]$ and also with that $(2.459(5) \AA)$ found in tri-p-tolyltin bromide quinoline $N$-oxide [10].

\section{Acknowledgments}

This research has been generously supported by the National Science Council for R \& D, Malaysia (Grant No. 2-07-04-06) and the University of Malaya (PJP 66/95). We are grateful to the S.E.R.C (U.K.) and the University of Reading for funding the purchase of the Image Plate System.

\section{References}

1 S.W. Ng, V.G. Kumar Das, B.W. Skelton and A.H. White, J. Organomet. Chem., 377 (1989) 211; S.W. Ng, V.G. Kumar Das, G. Pelizzi and F. Vitali, J. Crystallogr. Spectrosc. Res., 20 (1990) 491.

2 S. Chandra, B.D. James, R.J. Magee, W.C. Patalinghug, B.W. Skelton and A.H. White, J. Organomet. Chem., 346 (1988) 7.

3 E.M. Holt, F.A.K. Nasser, A. Wilson and J.J. Zuckerman, Organometallics, 4 (1985) 2073.

$4 \quad$ E.R.T. Tiekink and G. Winter, J. Organomet. Chem., 314 (1986) 85.

5 S.W. Ng and V.G. Kumar Das, J. Crystallogr. Spectrosc. Res., 23 (1993) 925.

6 T.N. Srivastava, M.A. Siddiqui and K. Srivastava, Ind. J. Chem., 26A (1987) 1840.

$7 \quad$ W. Kabsch, J. Appl. Crystallogr., 21 (1988) 916.

$8 \quad$ G.M. Sheldrick, Acta Crystallogr., A46 (1990) 467.

9 G.M. Sheldrick, SHELXL-93, University of Göttingen, Germany (1993).

10 V.G. Kumar Das, C.K. Yap, S.W. Ng, W. Chen and T.C.W. Mak, J. Organomet. Chem., 311 (1986) 289.

11 N. Donoghue and E.R.T. Tiekink, J. Organomet. Chem., 420 (1990) 179.

12 S.W. Ng, Z. Kristallogr., 209 (1994) 813.

13 S.W. Ng and V.G. Kumar Das, Z. Kristallogr., 210 (1995) 133.

Received: April 13, 1995 - Accepted: May 4, 1995 - Received revised camera-ready manuscript: June 20, 1995 
